\title{
Solicitação De Exames Na Internação De Um Hospital Escola
}

\author{
Butzke, B.L.; Butzke, M.; Butzke, M.; Jimenez, L.F.; Uzeika, L.; Toralles, E.K.; \\ Apresentador: Bruna Letícia Butzke
}

\section{Resumo}

Introdução: O número de exames solicitados durante as internações hospitalares vem aumentando em todo o mundo nas últimas décadas. Embora os testes diagnósticos auxiliem no diagnóstico e tratamento dos pacientes, sabe-se que grande parte dos exames solicitados não são necessários para o adequado manejo dos pacientes. $\mathrm{O}$ excesso de solicitações acarreta grande custo financeiro, seja ao paciente ou ao sistema de saúde, além da ansiedade gerada para o paciente pela realização do exame e possíveis diagnósticos equivocados, devido aos resultados falsos-positivos e falsos-negativos. Em março de 2010, o Hospital de Clínicas de Porto Alegre (HCPA) realizou um Grand Round Acadêmico sobre solicitação racional de exames laboratoriais com objetivo de conscientizar o corpo hospitalar e, a partir de março, foi bloqueada a solicitação de pedidos repetidos do mesmo exame em menos de 48 horas para hemograma e dosagens séricas de potássio, creatinina, sódio e uréia. Método: Análise da base de dados do sistema referentes a solicitação de exames laboratoriais por paciente-dia (E/PD). Os dados foram retirados do Sistema de Informações Gerenciais do HCPA. Foi analisada a variação percentual das taxas em relação ao ano anterior, correlacionado a variação com as intervenções realizadas em 2010. Resultados: Em 2004 eram solicitados em média 3,4 E/PD, em 2013 o número foi de 4,6 E/PD, conferindo um aumento total de 37\% em 10 anos. Entre os anos de 2004 e 2009, houve um aumento médio de $6,9 \%$ ao ano, atingindo o pico de 4,7 E/PD. Após as intervenções realizadas, nos anos de 2010 e 2011 houve uma redução de 8\% (4\% ao ano), e, após, um retorno à tendência de aumento, na taxa de 3\% ao ano até 2014. Conclusão: Há uma tendência de aumento da solicitação de exames para pacientes internados no HCPA nos últimos anos. As intervenções realizadas em 2010 se relacionaram a uma queda inicial na taxa de solicitação de exames, com um posterior retorno a tendência de aumento. Estes dados demonstram que, embora as intervenções tenham sido efetivas em diminuir a taxas de solicitação de exames, há necessidade de educação continuada dos profissionais, criação de protocolos e novas medidas administrativas para manter os resultados a longo prazo.

\section{Referência:}

Butzke, B.L.; Butzke, M.; Butzke, M.; Jimenez, L.F.; Uzeika, L.; Toralles, E.K.; Solicitação De Exames Na Internação De Um Hospital Escola. In: II Congresso Brasileiro de Medicina Hospitalar - II CBMH [= Blucher Medical Proceedings, vol.1, num.5] São Paulo: Editora Blucher, 2014. p.52

DOI 10.5151/medpro-II-cbmh-047 